\title{
The efficacy of different instruments combined with Nd:YAP in endodontic retreatment
}

\author{
Fan Cheng ${ }^{1,2}$, Yaqin $\mathrm{Zhu}^{1}$ \\ ${ }^{1}$ Department of General Dentistry, Shanghai Ninth People's Hospital, Shanghai Jiao Tong University School of Medicine, College of Stomatology, \\ Shanghai Jiao Tong University, National Center for Stomatology, National Clinical Research Center for Oral Diseases, Shanghai Key Laboratory \\ of Stomatology, Shanghai, China; ${ }^{2}$ Department of Endodontics, School and Hospital of Stomatology, Tongji University, Shanghai Engineering \\ Research Center of Tooth Restoration and Regeneration, Shanghai, China \\ Contributions: (I) Conception and design: Y Zhu; (II) Administrative support: Y Zhu; (III) Provision of study materials or patients: Y Zhu; (IV) \\ Collection and assembly of data: F Cheng; (V) Data analysis and interpretation: F Cheng; (VI) Manuscript writing: Both authors; (VII) Final approval \\ of manuscript: Both authors. \\ Correspondence to: Yaqin Zhu. Department of General Dentistry, Shanghai Ninth People's Hospital, Shanghai Jiao Tong University School of \\ Medicine, College of Stomatology, Shanghai Jiao Tong University, National Center for Stomatology, National Clinical Research Center for Oral \\ Diseases, Shanghai Key Laboratory of Stomatology, Shanghai, China. Email: zyq1590@163.com.
}

Background: To evaluate the efficiency of endodontic retreatment using different instruments and observe whether the Nd:YAP laser can assist.

Methods: Eighty premolars were selected, of which the root canals were prepared, and were filled with both gutta-percha and AH plus. The teeth were randomly divided into eight groups, respectively using and not using the Nd:YAP laser with the use of $\mathrm{H}$ files, Reciproc files, Mtwo $\mathrm{R}$ files, and Mtwo $\mathrm{R}+\mathrm{H}$ files to remove the root-canal filling material. The retreatment time of each sample was recorded, and the amount of residual gutta-percha was calculated by Image J.

Results: (I) In the four no-Nd:YAP laser groups, the Mtwo R group and Reciproc group took the least time, and there was no statistical difference between them $(\mathrm{P}>0.05)$. The Mtwo $\mathrm{R}+\mathrm{H}$ file group took longer than the Mtwo $\mathrm{R}$ group and Reciproc group $(\mathrm{P}<0.05)$. The $\mathrm{H}$ file group took the longest time $(\mathrm{P}<0.05)$. (II) In the $\mathrm{Nd}$ :YAP laser group, the $\mathrm{H}$ file group took the longest time $(\mathrm{P}<0.05)$, and there were no significant statistical difference between the other three groups ( $>0.05)$. (III) The Nd:YAP laser groups took a longer time than the no-Nd:YAP laser groups $(\mathrm{P}<0.05)$. (IV) All of the groups had residues. (V) The residues in the Mtwo R + H files group and the Reciproc group were the least among the four groups $(\mathrm{P}<0.05)$, and the residues in the Mtwo $\mathrm{R}$ group were the most $(\mathrm{P}<0.05)$. (VI) The residues in the Mtwo $\mathrm{R}$ and $\mathrm{H}$ file groups of the Nd:YAP laser groups were less than those of the no-Nd:YAP laser groups $(\mathrm{P}<0.05)$, and the residues in the Reciproc and the Mtwo $\mathrm{R}+\mathrm{H}$ file groups of the Nd:YAP laser group showed no statistical difference with that of the no-Nd:YAP laser group $(\mathrm{P}>0.05)$.

Conclusions: None of the experimental methods could altogether remove the root-filling material. The Nd:YAP laser could assist, but the procedure still took a long time and the efficiency of endodontic retreatment was limited. Using the Mtwo $\mathrm{R}+\mathrm{H}$ or Reciproc file was the most efficient.

Keywords: Root canal files; Nd:YAP laser; endodontic retreatment

Submitted Apr 11, 2021. Accepted for publication Jul 06, 2021.

doi: $10.21037 / \mathrm{atm}-21-2373$

View this article at: https://dx.doi.org/10.21037/atm-21-2373 


\section{Introduction}

Root canal therapy is the most common endodontic treatment for periapical periodontitis, but carries a risk of failure (1). Endodontic retreatment can be used to avoid extraction, to preserve teeth that failed in the first root canal treatment, and to reduce pain. Endodontic retreatment aims to clear the infection with a high success rate. Traditionally, hand tools such as the $\mathrm{H}$ file are used to remove gutta-percha. Further developments include the mechanical Mtwo R and Reciproc files, nickeltitanium (NiTi) endodontic instruments used for singlefile root canal preparation $(2,3)$. The Mtwo R files were designed for gutta-percha removal (4). Reciproc files which were produced using M-Wire technology were more resistant to fatigue and safer in preparing curved and compliacated canals when compared with traditional NiTi instruments (5). Damla Kirici reported that Reciproc files can be used in endodontic retreatment (6). The Nd:YAP laser is used for root canal disinfection, dental caries, and periodontal diseases, but Farge et al. (7) reported that it could be used for root canal treatment.

The current experiment aimed to elucidate the most efficient method of endodontic retreatment by comparing the working time and residual amount of gutta-percha when using different files with and without the assistance of the Nd:YAP laser.

We present the following article in accordance with the MDAR reporting checklist (available at https://dx.doi. org/10.21037/atm-21-2373).

\section{Methods}

All procedures performed in this study involving human participants were in accordance with the Declaration of Helsinki (as revised in 2013). Ethical approval for this investigation was given by the Research Ethics Committee, Shanghai Ninth People's Hospital, Shanghai Jiao Tong University School of Medicine (No.: SH9H-2021-T173-2) and informed consent was taken from all the patients.

\section{Specimen preparation}

The study specimens were 80 extracted human mandibular premolars that had a patent and single canal (length of the teeth, $18-21 \mathrm{~mm}$ ), stored in a $3 \% \mathrm{H}_{2} \mathrm{O}_{2}$ solution. The teeth were cleaned and shaped by size $15-40 \mathrm{~K}$ files (MANI, Japan) to the working length, which was $0.5 \mathrm{~mm}$ from the apical foramen determined by size $15 \mathrm{~K}$ files. EDTA (Premier, USA) and $2 \mathrm{~mL}$ of $50 \mathrm{~g} / \mathrm{L} \mathrm{NaClO}$ were used to rinse the canals while changing the files. Each canal was dried by paper point and filled with size 40, 25 and 20 gutta-percha (Dentsply, Germany) and AH plus (Morita, Japan) as sealant using a lateral compaction technique. Each tooth was radiographed in the buccolingual and mesiodistal views to ensure the effectiveness of the root-canal filling. The teeth were stored at $37^{\circ} \mathrm{C}$ for 14 days.

\section{Experimental grouping and treatments}

The samples were randomly divided into eight groups of ten samples with the following treatments.

\section{Group 1}

The root canals were re-instrumented using the Reciproc R25 (VDW, Germany) (Figure 1) firstly and Reciproc R50 instruments (Figure 1) secondly with the VDW silver Reciproc endo-motor in the Reciproc-All mode (Figure 2). The files were moved towards the apex using an in-and-out pecking motion until they reached the working length.

\section{Group 2}

The root canals were re-instrumented using the Reciproc R25 firstly and Reciproc R50 instruments secondly with the VDW silver Reciproc endo-motor in the Reciproc-All mode. The files were moved towards the apex using an inand-out pecking motion until they reached the working length. Then the optical fiber $(300 \mu \mathrm{m})$ of the Nd:YAP laser (LOKKI, France) (Figure 3) was inserted into the root canal to irradiate parallel with the root canal wall.

\section{Group 3}

The root canals were re-instrumented using size 15 , 0.05 taper Mtwo R files (Mtwo Retreatment Files, VDW, Germany) firstly and size 25, 0.05 taper Mtwo R files secondly (Figure 4) with an electric motor (NSK ENDOMATE DT, Japan) in the $300 \mathrm{r} / \mathrm{min}, 2.2 \mathrm{Ncm}$ mode. The files were moved towards the apex using an in-and-out pecking motion until they reached the working length.

\section{Group 4}

The root canals were re-instrumented using size 15 , 0.05 taper Mtwo R files firstly and size 25, 0.05 taper Mtwo $\mathrm{R}$ files secondly with an electric motor in the $300 \mathrm{r} / \mathrm{min}$, 2.2 Ncm mode. The files were moved towards the apex using an in-and-out pecking motion until they reached the 


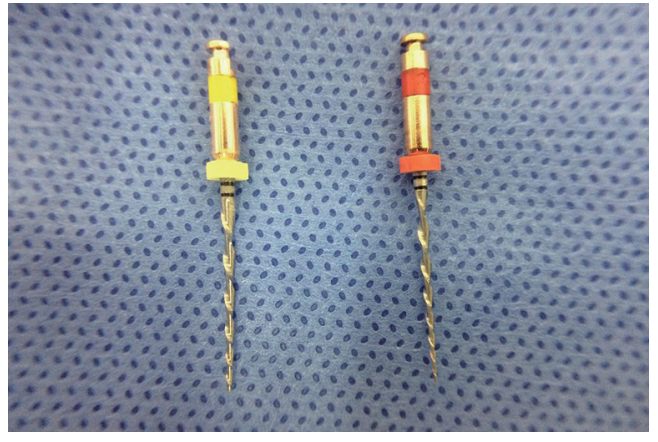

Figure 1 Reciproc files, R50 \& R25.

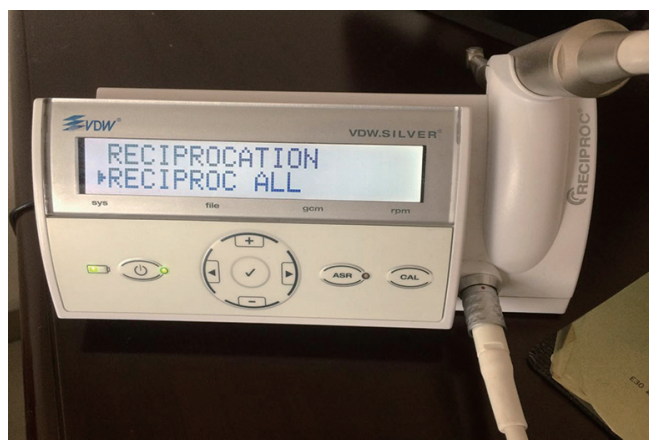

Figure 2 VDW Silver Reciproc endo-motor (Germany).

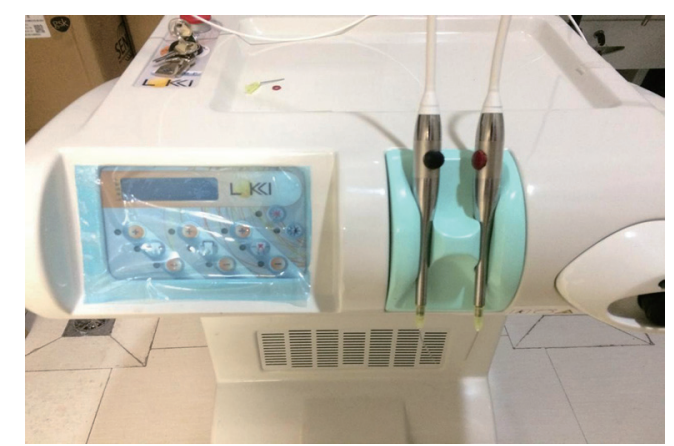

Figure $3 \mathrm{Nd}$ :YAP laser (LOKKI, France).

working length. Then the optical fiber of the Nd:YAP laser was inserted into the root canal to irradiate parallel with the root canal wall.

\section{Group 5}

The root canals were re-instrumented using size 15, 0.05 taper Mtwo R files firstly and size 25, 0.05 taper Mtwo $\mathrm{R}$ files secondly with an electric motor in the $300 \mathrm{r} / \mathrm{min}$, $2.2 \mathrm{Ncm}$ mode. Then, size 40, 0.02 taper $\mathrm{H}$ files (MANI,

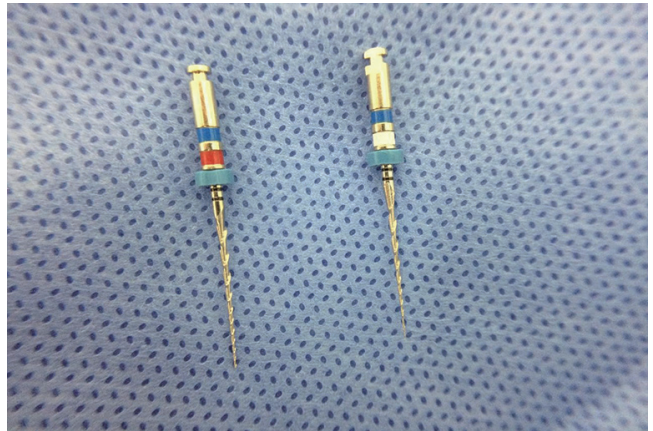

Figure 4 Mtwo R files, size 25, 0.05 taper (left) \& size 15, 0.05 taper (right).

Japan) were used to prepare the root canals. All the files were moved towards the apex using an in-and-out pecking motion until they reached the working length.

\section{Group 6}

The root canals were re-instrumented using size 15 , 0.05 taper Mtwo R files firstly and size 25, 0.05 taper Mtwo $\mathrm{R}$ files secondly with an electric motor in the $300 \mathrm{r} / \mathrm{min}$, $2.2 \mathrm{Ncm}$ mode. Then, size 40, 0.02 taper H-type files were used to prepare the root canals. All the files were moved towards the apex using an in-and-out pecking motion until they reached the working length. Finally, the optical fiber of the Nd:YAP laser was inserted into the root canal to irradiate parallel with the root canal wall.

\section{Group 7}

The root canals were re-instrumented using $\mathrm{H}$ files (size 15, 0.02 taper up to size 40, 0.02 taper) by hand. All the files were moved towards the apex using an in-and-out pecking motion until they reached the working length.

\section{Group 8}

The root canals were re-instrumented using $\mathrm{H}$ files size 15 , 0.02 taper up to size 40, 0.02 taper by hand. All the files were moved towards the apex using an in-and-out pecking motion until they reached the working length. Then the optical fiber of the Nd:YAP laser was inserted into the root canal to irradiate parallel with the root canal wall.

EDTA (excepting Reciproc) and $2 \mathrm{~mL}$ of $50 \mathrm{~g} / \mathrm{L} \mathrm{NaClO}$ were used to rinse the canals while changing the files. Each file finished the work when unimpeded to the apex and the last file of each group finished the work when the gum was invisible on the file. The Nd:YAP laser was used at $10 \mathrm{~Hz} / 2 \times 10^{-4} \mathrm{~kJ} / \mathrm{s}$. The optical fiber was inserted into the 
Page 4 of 9

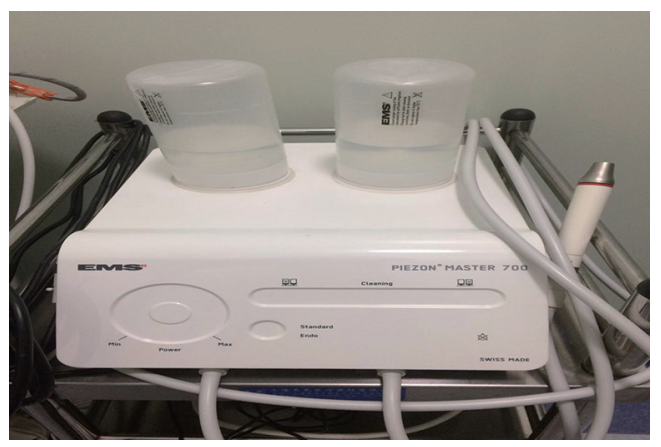

Figure 5 EMS Piezon Master (Switzerland).

Table 1 Comparison of the working time (T) of each group (s, $\bar{x} \pm \mathrm{s})$

\begin{tabular}{lcc}
\hline \multirow{2}{*}{ Group } & \multicolumn{2}{c}{ Working time $(\mathrm{T})$} \\
\cline { 2 - 3 } & No-Nd:YAP & Nd:YAP \\
\hline Reciproc & $363.2 \pm 45.8$ & $527.1 \pm 60.0$ \\
Mtwo R & $370.4 \pm 32.9$ & $527.6 \pm 53.4$ \\
Mtwo R + H & $454.1 \pm 55.4$ & $591.4 \pm 72.0$ \\
H & $732.1 \pm 112.7$ & $859.1 \pm 133.7$ \\
\hline
\end{tabular}

root canal to irradiate parallel with the root canal wall, and did not extend to the apex. While using the laser, $50 \mathrm{~g} / \mathrm{L}$ $\mathrm{NaClO}$ was used to rinse the canals. In each group, after all of the above treatments, $\mathrm{NaClO}$ was used to rinse the canals ultrasonically with the EMS Piezon Master (EMS, ENDO K15 $21 \mathrm{~mm}$, Switzerland) (Figure 5) until the flushing liquid was clear and there was no visible root-filling debris. The same operator carried out all the retreatments. Each set of Mtwo R files was used for the preparation of three root canals and then discarded. According to the manufacturer's instructions, one Reciproc file can only be used in one root canal, and the cutting force is strong.

\section{Efficiency evaluation}

\section{Working time $(T)$ of each group}

The total working time of each sample in all the retreatment procedures was recorded, including the time of changing the file and rinsing the canal.

\section{Residual root-canal filling material (R) of each group} Carborundum (silicon carbide) burrs (MANI TR-11, Japan) were used to groove the teeth longitudinally on the buccal and lingual surfaces to facilitate splitting into halves by chisel. The teeth were photographed under $\times 8$ magnification and Image J software (National Institutes of Health, USA) was used to analyze and calculate the percentage area of residual root-filling material occupying the whole canal of each sample.

\section{Statistical analysis}

SPSS 19.0 software was used for statistical analyses.

\section{Results}

Both $\mathrm{T}$ and $\mathrm{R}$ of each group were in a normal distribution. The variance of $T$ and $\mathrm{R}$ among the four Nd:YAP groups and the four no-Nd:YAP groups was not homogeneous, so Mann-Whitney tests were used to compare $\mathrm{T}$ and $\mathrm{R}$ among the four groups of Nd:YAP or no-Nd:YAP. The variance of $\mathrm{T}$ and $\mathrm{R}$ between the two groups of Nd:YAP and no$\mathrm{Nd}$ :YAP was homogeneous, so two independent samples $t$-tests were used to compare $\mathrm{T}$ and $\mathrm{R}$ between the two groups of Nd:YAP and no-Nd:YAP. The inspection standard was $\alpha=0.05$.

Comparison of the working time (T) of each group (Table 1, Figure 6A)

In the no-Nd:YAP laser group, the Mtwo R and Reciproc groups took the least time and there was no statistical difference between them $(\mathrm{P}>0.05)$; the Mtwo $\mathrm{R}+\mathrm{H}$ file group took a longer time than the Mtwo $\mathrm{R}$ and Reciproc groups $(\mathrm{P}<0.05)$; the $\mathrm{H}$ file group took the longest time $(\mathrm{P}<0.05)$.

In the Nd:YAP laser group, the $\mathrm{H}$ file group took the longest time $(\mathrm{P}<0.05)$, and there were no significant statistical difference between the other three groups $(\mathrm{P}>0.05)$.

The four Nd:YAP laser groups took a longer time than the four no-Nd:YAP laser groups $(\mathrm{P}<0.05)$.

\section{Comparison of the amount of residual root-canal filling (S)} of each group (Table 2, Figure 6B)

All of the groups had residues.

The residues in the Mtwo $\mathrm{R}+\mathrm{H}$ and the Reciproc groups were the least among the four groups $(\mathrm{P}<0.05)$, and there were no statistical difference between them $(\mathrm{P}>0.05)$; and the residues in the Mtwo $\mathrm{R}$ group were the most $(\mathrm{P}<0.05)$.

The residues in the Mtwo $\mathrm{R}$ and the $\mathrm{H}$ file groups of the $\mathrm{Nd}$ :YAP laser group were less than those of the no-Nd:YAP 

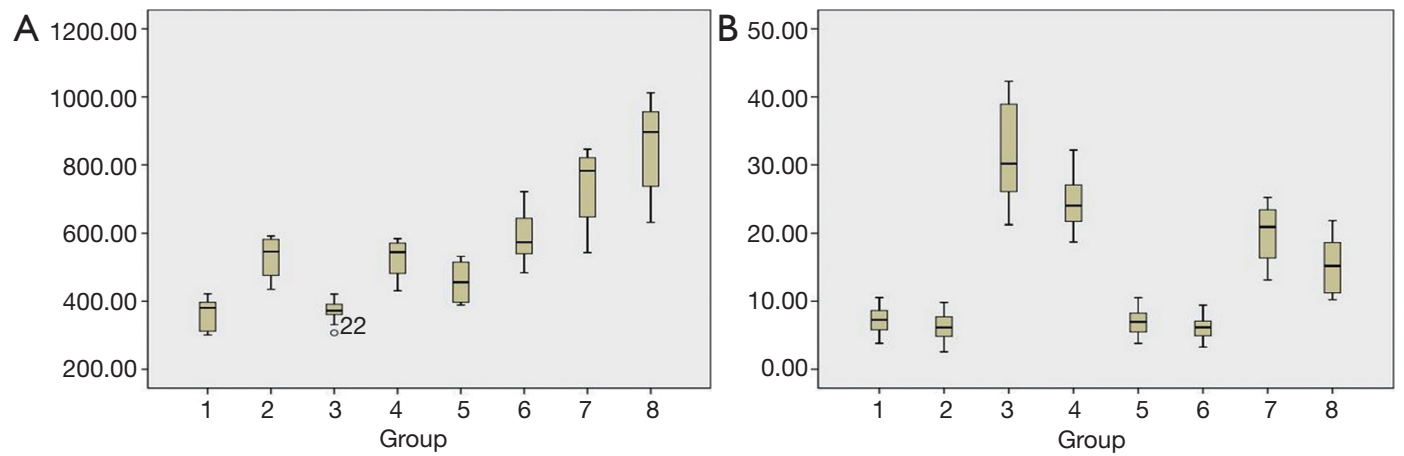

Figure 6 The box plots of the working time T (s) and residues R (\%) of each group. (A) Distribution of the working time T (s) of each group (median, quartiles, marginal value). (B) Distribution of the amount of residual root-canal filling material $\mathrm{R}$ (\%) of each group (median, quartiles, marginal value).

Table 2 Comparison of the amount of residual root canal filling material of each group $(\%, \bar{x} \pm \mathrm{s})$

\begin{tabular}{lcc}
\hline \multirow{2}{*}{ Group } & \multicolumn{2}{c}{ Residue (R) } \\
\cline { 2 - 3 } & No-Nd:YAP & Nd:YAP \\
\hline Reciproc & $7.20 \pm 2.16$ & $6.28 \pm 2.30$ \\
Mtwo R & $31.46 \pm 7.36$ & $24.58 \pm 4.30$ \\
Mtwo R + H & $7.00 \pm 2.07$ & $6.08 \pm 1.75$ \\
H & $20.10 \pm 4.18$ & $15.26 \pm 4.08$ \\
\hline
\end{tabular}

laser groups $(\mathrm{P}<0.05)$, and the residues in the Reciproc and the Mtwo $\mathrm{R}+\mathrm{H}$ file groups of the Nd:YAP laser group showed no statistical difference with those of the no$\mathrm{Nd}$ :YAP laser groups $(\mathrm{P}>0.05)$.

\section{Discussion}

The direct cause of the failure of root canal treatment was that the infected focus were not cleared, including the following situations: root canal filling was not in place and not tightly closed (such as C-shaped root canal), and the distance of more than $2 \mathrm{~mm}$ from the apical foramen was generally considered to be unqualified root filling; root canal omissions (e.g., mesial buccal root canal called MB2 of maxillary first molar); overfilling of the canal pushed the infection out of root foramen; microbial reinfection after plasticizing treatment; microleakage of the dental restoration. The aim of root canal retherapy was to clear the apical infection again and restore the periapical tissue to health. For teeth that have failed a first endodontic treatment and that have a focus of apex $<5 \mathrm{~mm}^{2}$, nonsurgical endodontic retreatment is the best choice (8). However, the complexity of the root canal system and variations in its morphology can create difficulties with endodontic treatment and retreatment $(9,10)$. Broken instruments, root canal perforation and root fracture are causes of treatment failure. Therefore, endodontic retreatment was an important means to preserve the affected teeth that have failed in first root canal treatment. H-type file was the tradional hand-use files which was made of stainless steel. It can remove the gutta-purcha from the root canal thanks to its special shaped cross section. Because of their flexibility and toughness, NiTi instruments are more secure for use in the preparation of curved root canals and have improved the success rate of endodontic treatment and retreatment $(11,12)$. In addition, compared with traditional instruments, NiTi instruments can effectively shorten the time of root canal preparation. As well as the traditional hand-use $\mathrm{H}$ file, there is a variety of mechanical NiTi files for the removal of root-canal filling materials, including the Mtwo R file and Protaper Universal System, etc. (13). The transversal surface of the Mtwo $\mathrm{R}$ file is the $\mathrm{S}$ type, which makes for strong cutting effectiveness (4). Two types of Mtwo R files should be used together: size 15, 0.05 taper, and size 25, 0.05 taper. The tip of the size 15 file will effectively create a root canal treatment pathway. With the recent development of mechanical NiTi instruments, single-file root canal systems gradually began to be applied in the clinic, including the Wave One and Reciproc file, which has shortened the clinical operation time and reduced the difficulties of retreatment (3). Using a single file not only means completion of root canal preparation without changing files but also shows that one instrument can prepare a root canal. However, using a single file without the procedure 
of changing files has a higher risk of breakage in root canal preparation compared with traditional instruments. Thus single files must meet higher standards of root canal adaptability and metal elasticity. Different from traditional $\mathrm{NiTi}$ instruments processed and formed in the A style, Wave One and Reciproc files are processed and formed in the $\mathrm{M}$ style. The $3-\mathrm{mm}$ tip has a larger taper and the upper taper is smaller, which enhances metal elasticity and fatigue resistance (2). Besides this, different from the continuous rotation movement in 360 degrees of traditional NiTi instruments, the reciprocating motion in which the clockwise rotation angle is more significant than the counterclockwise rotation enhances the fatigue resistance of the metal, reducing the risk of breaking during working, and also leads the file to the tooth's apex $(14,15)$. Due to the sharp cutting force and unique movement of the single file, Reciproc can wrap debris from the wall of the root canal onto the file without the use of EDTA to remove it (16).

With the development of laser technology, semiconductor and crystal lasers have been used in root canal disinfection, dental caries removal, desensitization, periodontal pocket treatment, treatment of recurrent aphthous ulcer and oral surgery $(17,18)$. The working substance of Nd:YAP laser is yttrium aluminate crystal doped with neodymium, and the water absorption rate is 2.700832 (19). Nd:YAP laser was developed in 1994, and was first used in the treatment of oral diseases by Professor Bonin of the University of Lyon in France. Nd:YAP laser can be used for root canal disinfection, endodontic retreatment, resection of apical occluding, removal of gingival fibroma, treatment of dentine hypersensitivity and periimplantitis. Blum's study showed that Nd:YAP laser can be quickly absorbed by restoractive materials and root filling materials, thus confirming its potential use in removing these materials during endodonic retreatment (20). The laser method has the following advantages: the laser fiber is mainly made of silicon dioxide, which has a certain softness and is easy to extend into the depth of the root canal. In clinical practice, the laser irradiation on metal and dentin can be used to control the firing position to avoid excessive damage of dentin. Compared with ultrasonic vibration method, the risk of root fracture caused by laser irradiation is lower (21). The energy produced by the laser beam can effectively kill bacteria in the root canal, make the smear layer instantly vaporize and achieve proper root canal disinfection. Its high energy can melt the dentinal tubules on the root canal wall, achieved a good effect of blocking the dentinal tubules and reduces the possibility of secondary infection (22). Early studies reported that Nd:YAP could be used to remove root canal filling material and assist in endodontic retreatment. Jiang et al. (18) conducted an vitro study that found the Er:YAG laser could help remove residual gutta-percha from the root canal during retreatment. In earlier literature, both Nd:YAP and Nd:YAG laser were used to remove guttapercha $(7,22)$.

Among the present four no-Nd:YAP laser groups, the Mtwo $\mathrm{R}$ and Reciproc groups took the least time (Figure $6 \mathrm{~A}$ groups 1, 3, 5, 7). These were mechanic NiTi files, which were more efficient than the manual $\mathrm{H}$ files. In addition, during the procedure on each sample, the Mtwo $\mathrm{R}$ and Reciproc files only needed to be changed once, whereas the $\mathrm{H}$ files needed to be replaced three times. There was no statistical difference between the Mtwo R and the Reciproc groups, possibly because the time taken to change files during the procedure was the same in both groups, and there was no significant difference in the efficiency of the $\mathrm{NiTi}$ instruments in root canal preparation. The working time of the Mtwo $\mathrm{R}+\mathrm{H}$ group was longer than that of the Mtwo R and Reciproc groups because it was more involved.

In the Nd:YAP laser group, the $\mathrm{H}$ file group took the longest time, and there was no significant statistical difference between the other three groups (Figure $6 \mathrm{~A}$ groups 2, 4, 6, 8). The reason may be that the mechanical NiTi files were more efficient than the manual $\mathrm{H}$ files, and the time taken for changing files in the $\mathrm{H}$ file group was the longest. The time required for preparation was significantly prolonged and the time variability was more considerable when the Nd:YAP laser was involved in the preparation process, resulting in no significant difference between the Mtwo R, Reciproc, and the Mtwo $\mathrm{R}+\mathrm{H}$ file groups.

All four groups in the Nd:YAP laser group took a longer time than no-Nd:YAP laser groups (Figure $6 A$ groups 1 and 2, 3 and 4, 5 and 6, 7 and 8 ), and the Nd:YAP group was significantly longer than the Nd:YAP group in terms of preparation time by an average of 120-160 s.

All of the groups had residues, which means none of the experimental methods could altogether remove the root-canal filling material. The residues in the Mtwo $\mathrm{R}+$ $\mathrm{H}$ and the Reciproc file groups were the least among the 4 groups, and the residues in the Mtwo R group were the most, whether using Nd:YAP laser or not (Figure $6 B$ groups 1, 3, 5, 7 or 2, 4, 6, 8; Figure 7). The possible reason was the size 15, 0.05 taper and size 25, 0.05 taper Mtwo R files were an excellent size for penetrating the root-canal filling material and establishing the root canal pathway, and the size 40, 0.02 taper was used to prepare the root canal before 

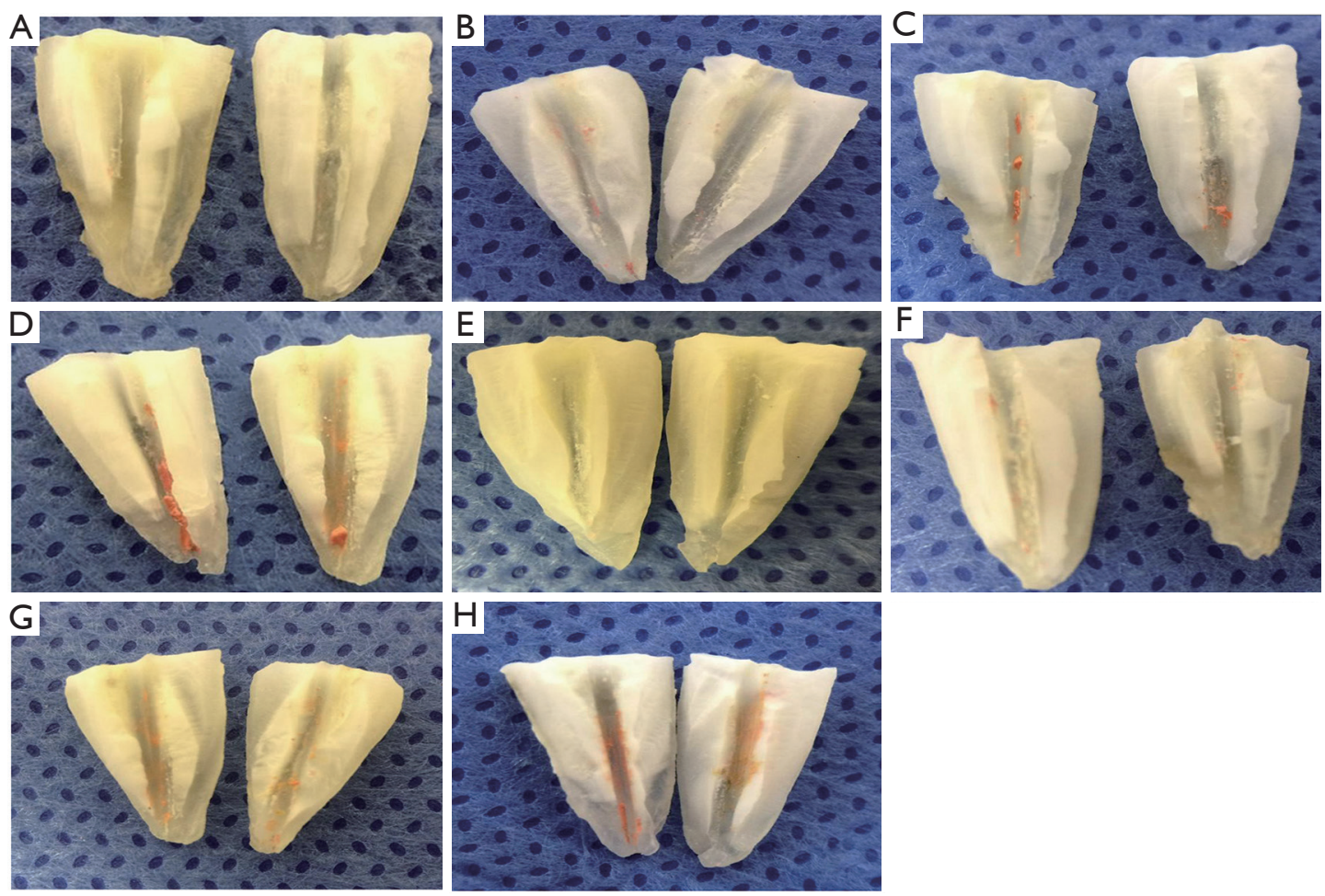

Figure 7 The photos of the residues of each group. (A) Nd:YAP Reciproc. (B) No-Nd:YAP Reciproc. (C) Nd:YAP Mtwo R file. (D) NoNd:YAP Mtwo R file. (E) Nd:YAP Mtwo R + H file. (F) No-Nd:YAP Mtwo R + H file. (G) Nd:YAP H file. (H) No-Nd:YAP H file.

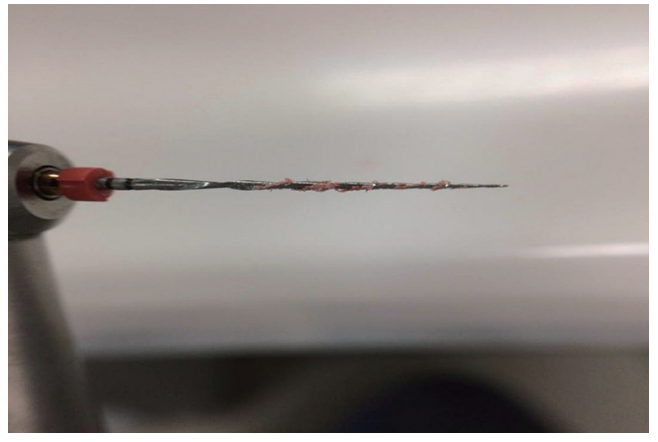

Figure 8 Debris wrapped on the Reciproc file.

retreatment, which meant the gutta-percha in the apical third could only be penetrated but not removed in the Mtwo $\mathrm{R}$ group. The largest size of the $\mathrm{H}$ files was 40, 0.02 taper, and the operation mode was manual, with an efficiency that was more miserable than that of the mechanical NiTi files. In the Reciproc group, the larger files were size 50, of which the taper graduates to 0.04 . Both the size and the taper of Reciproc files were more extensive than that of the root canal before retreatment.

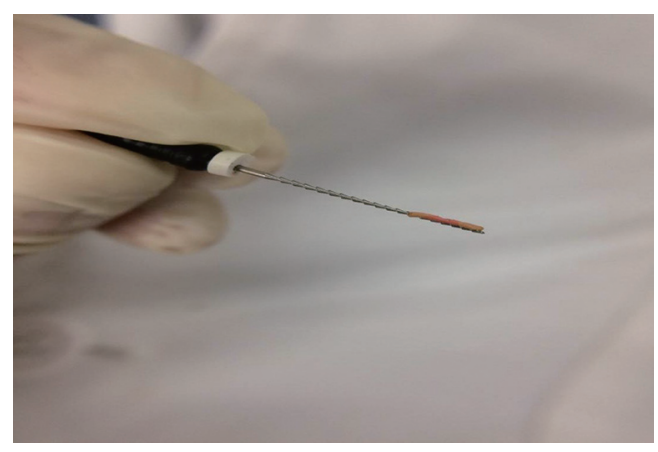

Figure $9 \mathrm{H}$ file of size 40 could help Mtwo R file to remove guttapercha.

Moreover, the Reciproc file could wrap debris from the wall of the root canal onto the file without the use of EDTA to flush it out (Figure 8). In the Mtwo $\mathrm{R}+\mathrm{H}$ group, the $\mathrm{H}$ file of size 40, 0.02 taper, could help remove the guttapercha in the apical third, which the Mtwo R could not remove (Figure 9).

The residues in the Mtwo $\mathrm{R}$ and in $\mathrm{H}$ file groups of the $\mathrm{Nd}$ :YAP laser group were less than those in the no-Nd:YAP 


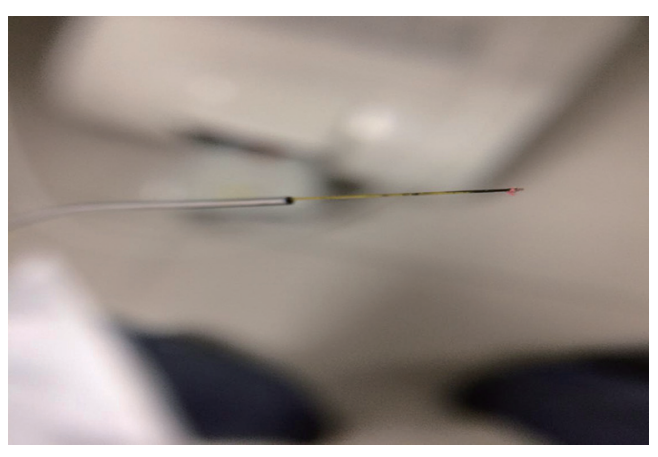

Figure 10 Debris on the optical fiber of the Nd:YAP laser.

laser groups, and the residues in the Reciproc and Mtwo R $+\mathrm{H}$ file groups of the Nd:YAP laser group had no statistical difference with that of the no-Nd:YAP laser groups (Figure $6 B$ groups 1 and 2, 3 and 4, 5 and 6, 7 and 8; Figure 7). The Nd:YAP laser can carbonize dentin debris and residual guttapercha (Figure 10), melt dentinal tubules on the root canal wall and remove the smear layer with its energy. In the Reciproc and Mtwo R + H file groups, the files had removed most of the gutta-percha before the Nd:YAP laser was used, and the effect produced by Nd:YAP laser was probably not enough to clear the remaining gutta-percha.

\section{Conclusions}

None of the experimental methods could completely remove the root-canal filling material. The Nd:YAP laser could assist in remove the root-canal filling material, but the retreatment procedure took longer, and the efficiency of endodontic retreatment was limited. Using Mtwo $\mathrm{R}+\mathrm{H}$ and Reciproc files showed the best efficiency.

\section{Acknowledgments}

Funding: This work was supported by the National Natural Science Foundation of China (grant No. 81700949).

\section{Footnote}

Reporting Checklist: The authors have completed the MDAR reporting checklist. Available at https://dx.doi. org/10.21037/atm-21-2373

Data Sharing Statement: Available at https://dx.doi. org/10.21037/atm-21-2373
Conflicts of Interest: Both authors have completed the ICMJE uniform disclosure form (available at https://dx.doi. org/10.21037/atm-21-2373). The authors have no conflicts of interest to declare.

Ethical Statement: The authors are accountable for all aspects of the work in ensuring that questions related to the accuracy or integrity of any part of the work are appropriately investigated and resolved. All procedures performed in this study involving human participants were in accordance with the Declaration of Helsinki (as revised in 2013). The study was approved by the Research Ethics Committee, Shanghai Ninth People's Hospital, Shanghai Jiao Tong University School of Medicine (No.: SH9H2021-T173-2) and informed consent was taken from all the patients.

Open Access Statement: This is an Open Access article distributed in accordance with the Creative Commons Attribution-NonCommercial-NoDerivs 4.0 International License (CC BY-NC-ND 4.0), which permits the noncommercial replication and distribution of the article with the strict proviso that no changes or edits are made and the original work is properly cited (including links to both the formal publication through the relevant DOI and the license). See: https://creativecommons.org/licenses/by-nc-nd/4.0/.

\section{References}

1. Stoll R, Betke K, Stachniss V. The influence of different factors on the survival of root canal fillings: a 10-year retrospective study. J Endod 2005;31:783-90.

2. Gambarini G, Giansiracusa Rubini A, Sannino G, et al. Erratum to: Cutting efficiency of nickel-titanium rotary and reciprocating instruments after prolonged use. Odontology 2016;104:82. Erratum for: Odontology 2016;104:77-81.

3. Marfisi K, Mercadé M, Plotino G, et al. Efficacy of Reciproc ${ }^{\circledR}$ and Profile ${ }^{\circledR}$ Instruments in the Removal of Gutta-Percha from Straight and Curved Root Canals ex Vivo. J Oral Maxillofac Res 2015;6:e1.

4. Khedmat S, Azari A, Shamshiri AR, et al. Efficacy of ProTaper and Mtwo Retreatment Files in Removal of Gutta-percha and GuttaFlow from Root Canals. Iran Endod J 2016;11:184-7.

5. Delai D, Jardine AP, Mestieri LB, et al. Efficacy of a thermally treated single file compared with rotary systems 
in endodontic retreatment of curved canals: a micro-CT study. Clin Oral Investig 2019;23:1837-44.

6. Kırıcı D, Demirbuga S, Karataş E. Micro-computed tomographic assessment of the residual filling volume, apical transportation, and crack formation after retreatment with reciproc and reciproc blue systems in curved root canals. J Endod 2020;46:238-43.

7. Farge $P$, Nahas $P$, Bonin P. In vitro study of a Nd:YAP laser in endodontic retreatment. J Endod 1998;24:359-63.

8. Zitzmann NU, Krastl G, Hecker H, et al. Endodontics or implants? A review of decisive criteria and guidelines for single tooth restorations and full arch reconstructions. Int Endod J 2009;42:757-74.

9. Corbella S, Taschieri S, Tsesis I, et al. Postextraction implant in sites with endodontic infection as an alternative to endodontic retreatment: a review of literature. J Oral Implantol 2013;39:399-405.

10. Imura N, Pinheiro ET, Gomes BP, et al. The outcome of endodontic treatment: a retrospective study of 2000 cases performed by a specialist. J Endod 2007;33:1278-82.

11. Chandrasekar, Ebenezar AV, Kumar M, et al. A comparative evaluation of gutta percha removal and extrusion of apical debris by rotary and hand files. J Clin Diagn Res 2014;8:ZC110-4.

12. Joseph $M$, Ahlawat J, Malhotra A, et al. In vitro evaluation of efficacy of different rotary instrument systems for gutta percha removal during root canal retreatment. J Clin Exp Dent 2016;8:e355-60.

13. Bernardes RA, Duarte MAH, Vivan RR, et al. Comparison of three retreatment techniques with ultrasonic activation in flattened canals using micro-computed tomography and scanning electron microscopy. Int Endod J 2016;49:890-7.

14. Gavini G, Caldeira CL, Akisue E, et al. Resistance to flexural fatigue of Reciproc R25 files under continuous

Cite this article as: Cheng F, Zhu Y. The efficacy of different instruments combined with Nd:YAP in endodontic retreatment. Ann Transl Med 2021;9(14):1141. doi: 10.21037/atm-21-2373 rotation and reciprocating movement. J Endod 2012;38:684-7.

15. Kim HC, Kwak SW, Cheung GS, et al. Cyclic fatigue and torsional resistance of two new nickel-titanium instruments used in reciprocation motion: Reciproc versus WaveOne. J Endod 2012;38:541-4.

16. Varela-Patiño P, Ibañez-Párraga A, Rivas-Mundiña $\mathrm{B}$, et al. Alternating versus continuous rotation: a comparative study of the effect on instrument life. J Endod 2010;36:157-9.

17. Ozkocak I, Sonat B. Evaluation of effects on the adhesion of various root canal sealers after Er:YAG laser and irrigants are used on the dentin surface. J Endod 2015;41:1331-6.

18. Jiang S, Zou T, Li D, et al. Effectiveness of sonic, ultrasonic, and photon-induced photoacoustic streaming activation of $\mathrm{NaOCl}$ on filling material removal following retreatment in oval canal anatomy. Photomed Laser Surg 2016;34:3-10.

19. Liu T, Huang Z, Ju Y, et al. Bactericidal efficacy of three parameters of $\mathrm{Nd}$ :YAP laser irradiation against Enterococcus faecalis compared with $\mathrm{NaOCl}$ irrigation. Lasers Med Sci 2019;34:359-66.

20. Blum JY, Peli JF, Abadie MJ. Effects of the Nd:YAP laser on coronal restorative materials: implications for endodontic retreatment. J Endod 2000;26:588-92.

21. Moshonov J, Peretz B, Brown T, et al. Cleaning of the root canal using Nd:YAP laser and its effect on the mineral content of the dentin. J Clin Laser Med Surg 2004;22:87-9.

22. Viducić D, Jukić S, Karlović Z, et al. Removal of guttapercha from root canals using an Nd:YAG laser. Int Endod J 2003;36:670-3. 